\title{
Optimal dosing of antibiotics in critically ill patients by using continuous/extended infusions: a systematic review and meta-analysis
}

\author{
Clarence Chant ${ }^{1,2}$, Ann Leung ${ }^{1}$ and Jan O Friedrich ${ }^{2,3,4^{*}}$
}

\begin{abstract}
Introduction: The aim of this study was to determine whether using pharmacodynamic-based dosing of antimicrobials, such as extended/continuous infusions, in critically ill patients is associated with improved outcomes as compared with traditional dosing methods.

Methods: We searched Medline, HealthStar, EMBASE, Cochrane Clinical Trial Registry, and CINAHL from inception to September 2013 without language restrictions for studies comparing the use of extended/continuous infusions with traditional dosing. Two authors independently selected studies, extracted data on methodology and outcomes, and performed quality assessment. Meta-analyses were performed by using random-effects models.

Results: Of 1,319 citations, 13 randomized controlled trials (RCTs) ( $n=782$ patients) and 13 cohort studies $(n=2,117$ patients) met the inclusion criteria. Compared with traditional non-pharmacodynamic-based dosing, RCTs of continuous/ extended infusions significantly reduced clinical failure rates (relative risk (RR) $0.68 ; 95 \%$ confidence interval (CI) 0.49 to $0.94, P=0.02$ ) and intensive care unit length of stay (mean difference, $-1.5 ; 95 \% \mathrm{Cl},-2.8$ to -0.2 days, $P=0.02$ ), but not mortality (RR, $0.87 ; 95 \% \mathrm{Cl}, 0.64$ to $1.19 ; P=0.38$ ). No significant between-trial heterogeneity was found for these analyses $\left(P^{2}=0\right)$. Reduced mortality rates almost achieved statistical significance when the results of all included studies (RCTs and cohort studies) were pooled (RR, 0.83; 95\% Cl, 0.69 to 1.00; $P=0.054$ ).

Conclusions: Pooled results from small RCTs suggest reduced clinical failure rates and intensive care unit length-of-stay when using continuous/extended infusions of antibiotics in critically ill patients. Reduced mortality rates almost achieved statistical significance when the results of RCTs were combined with cohort studies. These results support the conduct of adequately powered RCTs to define better the utility of continuous/extended infusions in the era of antibiotic resistance.
\end{abstract}

\section{Introduction}

Optimal use of antimicrobials is crucial in the critical care setting, especially in an era of increasing antibiotic resistance and lack of new antimicrobial development [1]. Interest is growing in alternative antimicrobial dosing strategies that are better aligned with the antimicrobial's pharmacodynamic properties, and the potential of this approach to improve patient outcomes [2]. Given the highly variable and often unknown pharmacokinetics of antimicrobials in critically ill patients as compared with other hospitalized patients, alignment with the

\footnotetext{
* Correspondence: j.friedrich@utoronto.ca

${ }^{2}$ Li Ka Shing Knowledge Institute, St. Michael's Hospital, Toronto, Canada ${ }^{3}$ Interdepartmental Division of Critical Care, University of Toronto, Toronto, Canada

Full list of author information is available at the end of the article
}

pharmacodynamics (PDs) of the antimicrobials is even more important [3]. Antimicrobial pharmacodynamics refers to the effects of a drug on microorganisms in relation to the drug's concentration within the body (that is, pharmacokinetics, PCKs). The PD of beta-lactam antimicrobials (for example, penicillins, cephalosporins) are termed time-dependent, as their effects are best correlated with the amount of time that the serum concentrations of the antimicrobial are above the minimum inhibitory concentration (MIC) of the microorganism. Other antibiotics, such as fluoroquinolones and aminoglycosides, have PD properties termed concentration-dependent killing, given that their effects correlate best with peak concentration/MIC ratio and/or area under the concentration-time curve/MIC ratio [3]. To maximize microorganism eradication, several dosing methods that

\section{Biomed Central}


exploit the antimicrobial PD properties have been investigated. These include administration of timedependent antimicrobials via extended (for example, over a period of 3 to 4 hours) or continuous infusion, as compared with traditional intermittent infusions (for example, over a period of 30 minutes), or altering doses based on both patient-specific pharmacokinetic parameters and the MIC of the target organism (also known as dual individualization) $[3,4]$.

Unless clinical benefits are compelling, widespread clinical application of pharmacodynamics-based dosing (PDD) is unlikely, given the multitude of barriers to their implementation. These barriers include (a) identification of the types of patients that would benefit the most, with the critically ill patient population being the most obvious choice, given their heightened risk of infectiousrelated morbidity and mortality and increasing resistance; (b) requirement of significant practice changes in microbiology, such as routine MIC determination by using more accurate nonautomated techniques; (c) better-defined pharmacokinetics of antimicrobials in patients in the intensive care unit (ICU) with varying degrees of renal and hepatic dysfunction, as well as the extent of medication removal by a variety of renalreplacement therapies; and (d) methods to manage the need of a dedicated intravenous line for administration via continuous/extended infusions. To justify such changes, results of rigorously conducted and adequately powered RCTs in a population most likely to benefit (for instance, ICU patients) are needed, the design of which should be informed by comprehensive systematic review of current evidence. Previous systematic reviews that included both critically ill and non-critically ill patient populations have provided inconsistent results [5-7].

Therefore, to better define the current state of knowledge on this important topic and to update previously reported systematic reviews, we conducted a systematic review and meta-analysis comparing PD antimicrobial dosing with traditional non-PDD on clinical outcomes (mortality, clinical failure rates, and length-of-stay (LOS)) focusing on critically ill patients. We included both randomized and cohort studies but emphasized the results of the RCTs in the interpretation of the results.

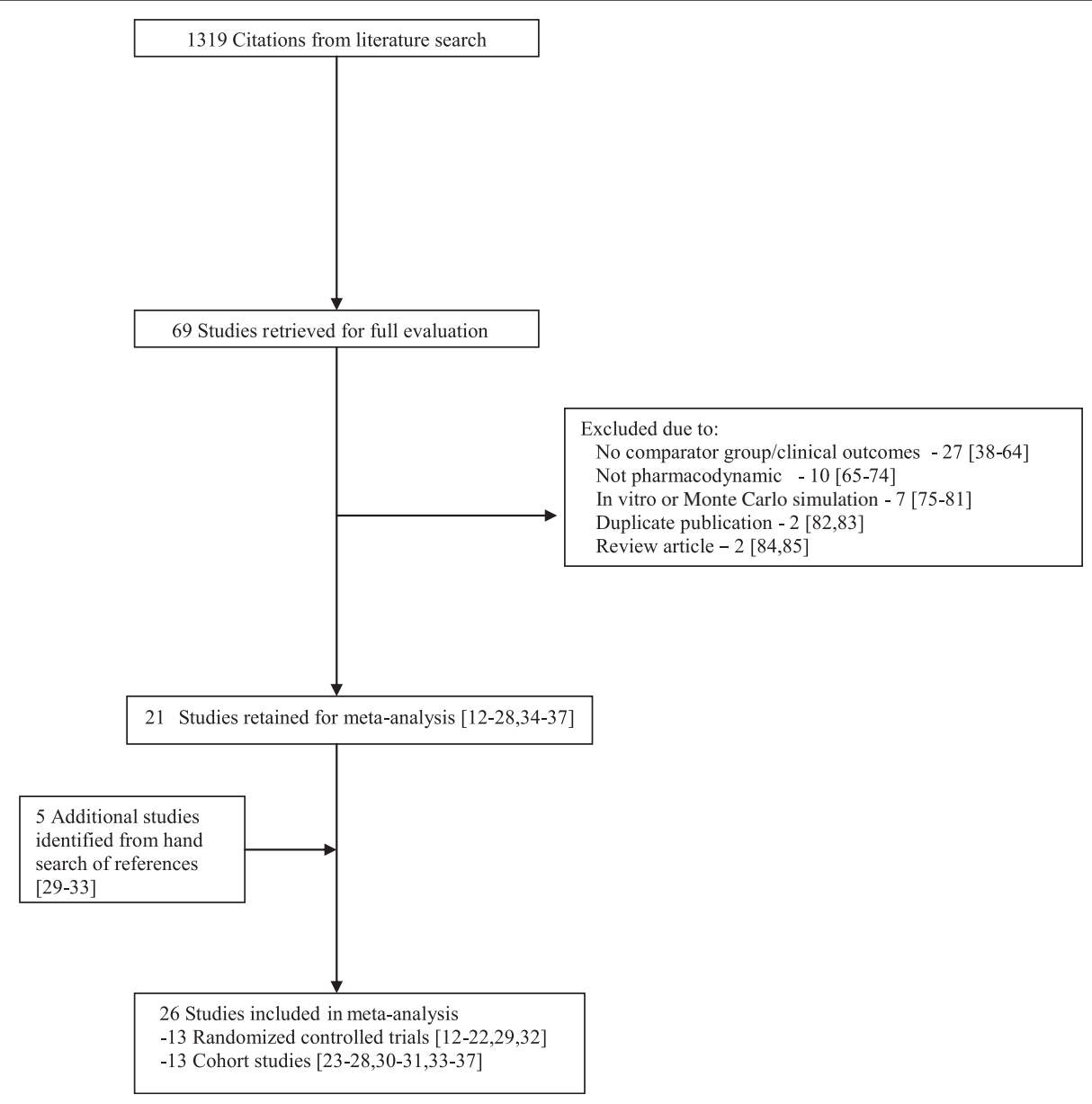

Figure 1 Flow chart of study selection. 
Table 1 Characteristics of selected studies for meta-analysis

\begin{tabular}{|c|c|c|c|c|c|c|c|c|}
\hline \multirow[t]{2}{*}{ Author (year) Country } & \multirow{2}{*}{$\begin{array}{l}\text { Type } \\
\text { of ICU }\end{array}$} & \multirow{2}{*}{$\begin{array}{l}\text { Study } \\
\text { design }\end{array}$} & \multirow[t]{2}{*}{ Infection } & \multicolumn{2}{|c|}{ Illness acuity } & \multirow[t]{2}{*}{ Study antibiotic } & \multirow[t]{2}{*}{ Control group } & \multirow[t]{2}{*}{ Intervention group } \\
\hline & & & & APACHE II & SAPS II & & & \\
\hline \multicolumn{9}{|l|}{ Randomized controlled trials } \\
\hline Georges (1999) France [12] & NR & $\mathrm{RCT}$ & $\begin{array}{l}\text { Pneumonia or bacteremia } \\
\text { with gram-negative bacilli }\end{array}$ & & 47 & Cefepime & $2 \mathrm{~g} \mathrm{q} 12 \mathrm{~h}$ & $4 \mathrm{~g} / \mathrm{d}$ as $\mathrm{Cl}$ \\
\hline Hanes (2000) USA [13] & $\mathrm{T}$ & $\mathrm{RCT}$ & Nosocomial pneumonia & 12 & & Ceftazidime & $2 \mathrm{~g}$ q8h (0.5-h infusion) & $\begin{array}{l}\text { LD, } 2 \mathrm{~g}(0.5-\mathrm{h} \text { infusion), then } \\
60 \mathrm{mg} / \mathrm{kg} / \text { day as Cl }\end{array}$ \\
\hline Nicolau (2001) USA [14] & $M S, N$ & $\mathrm{RCT}$ & VAP & 15 & & Ceftazidime & $2 \mathrm{~g}$ q8h (0.5-h infusion) & No LD $3 \mathrm{~g}$ over $24 \mathrm{~h}$ as Cl \\
\hline Wysocki (2001) France [15] & MS & $\mathrm{RCT}$ & $\begin{array}{l}\text { Any methicillin-resistant } \\
\text { staphylococcal infections }\end{array}$ & & $\mathrm{b}$ & Vancomycin & 15 mg/kg q12h (1-h infusion) & $\begin{array}{l}\text { LD, } 15 \mathrm{mg} / \mathrm{kg} \text { over } 1 \mathrm{~h} \text {, then } \\
30 \mathrm{mg} / \mathrm{kg} \text { as Cl }\end{array}$ \\
\hline Bujik (2002) Netherlands [16] & S & $\mathrm{RCT}$ (partial) & Severe intraabdominal infection & 15 & & Ceftazidime & $1.5 \mathrm{~g}$ tid (20-min infusion) & $\begin{array}{l}\mathrm{LD}, 1 \mathrm{~g} \text { over } 20 \mathrm{~min} \text {, then } \\
4.5 \mathrm{~g} / \mathrm{d} \text { as Cl }\end{array}$ \\
\hline Georges (2005) France [17] & $M, T$ & $\mathrm{RCT}$ & $\begin{array}{l}\text { Nosocomial pneumonia } \\
\text { or bacteremia }\end{array}$ & & 45 & Cefepime & $2 \mathrm{~g}$ q12h (0.5-h infusion) & No LD; $4 \mathrm{~g} \mathrm{Cl}$ \\
\hline Rafati (2006) Iran [18] & General & $\mathrm{RCT}$ & Sepsis from any source & 15 & & Piperacillin alone & $3 \mathrm{~g}$ q6h (0.5-h infusion) & $\begin{array}{l}\mathrm{LD}, 2 \mathrm{~g} \text { over } 0.5 \mathrm{~h} \text {, then } \\
8 \mathrm{~g} / 24 \mathrm{~h} \text { as } \mathrm{Cl}\end{array}$ \\
\hline Roberts (2007) Australia [19] & General & $\mathrm{RCT}$ & Sepsis from any source & 18 & & Ceftriaxone & $\mathrm{LD}=500 \mathrm{mg}$, then $2 \mathrm{~g}$ q24h & $\begin{array}{l}\mathrm{LD}, 500 \mathrm{mg} \text {, then } 2 \mathrm{~g} / 24 \mathrm{~h} \\
\text { as Cl }\end{array}$ \\
\hline Sakka (2007) Germany [20] & NR & $\mathrm{RCT}$ & Nosocomial pneumonia & 27 & 44 & Imipenem & $1 \mathrm{~g}$ q8h (40-min infusion) & $\begin{array}{l}\text { LD, } 1 \mathrm{~g} \text { over } 40 \mathrm{~min} \text {, then } \\
2 \mathrm{~g} / 24 \mathrm{hr} \text { as } \mathrm{Cl} \text { for } 3 \text { days, } \\
\text { then } 1 \mathrm{~g} \text { q8h over } 40 \mathrm{~min}\end{array}$ \\
\hline Adembri (2008) Italy [21] & $M, T$ & $\mathrm{RCT}$ & $\begin{array}{l}\text { Sepsis; glycopeptide resistant } \\
\text { or failure }\end{array}$ & & 45 & Linezolid & 600 mg q12h (0.5-h infusion) & $\begin{array}{l}\text { LD, } 300 \text { mg, Day 1: } 900 \mathrm{mg} \mathrm{Cl} \text {, } \\
\text { Day } 2 \text { onward: 1,200 mg Cl }\end{array}$ \\
\hline Wang (2009) China [32] & NR & $\mathrm{RCT}$ & Acinetobacter pneumonia & 19 & & Meropenem & $1 \mathrm{~g}$ q8h (1-h infusion) & 500 mg q6h as 3-h El \\
\hline Chytra (2012) Czech [22] & M & $\mathrm{RCT}$ & $\begin{array}{l}\text { Severe infection from } \\
\text { any source }\end{array}$ & 22 & & Meropenem & $2 \mathrm{~g}$ q8h (0.5-h infusion) & $\begin{array}{l}\mathrm{LD}, 2 \mathrm{~g} \text { over } 0.5 \mathrm{~h} \text {, then } 4 \mathrm{~g} / \mathrm{d} \\
\text { as } \mathrm{Cl}\end{array}$ \\
\hline \multirow[t]{2}{*}{ Dulhunty (2012) Australia [29] } & \multirow[t]{2}{*}{ NR } & \multirow[t]{2}{*}{$\mathrm{RCT}$} & \multirow[t]{2}{*}{ Severe sepsis } & \multirow[t]{2}{*}{22} & & \multirow{2}{*}{$\begin{array}{l}\text { Ticarcillin/clavulanate, } \\
\text { piperacillin/tazobactam, } \\
\text { or meropenem }\end{array}$} & Dose determined by MD & Dose determined by MD \\
\hline & & & & & & & All as intermittent infusion & All as $\mathrm{Cl}$ \\
\hline \multicolumn{9}{|l|}{ Cohort studies } \\
\hline Schentag (1984) USA [23] & NR & Cohort & $\begin{array}{l}\text { Gram-negative nosocomial } \\
\text { pneumonia }\end{array}$ & $N R$ & & Cefmenoxime & Fixed dose 1-2 g q6-8 h & $\begin{array}{l}\text { Integration of patient-specific } \\
\text { PCK with bacteria-specific } \\
\text { killing kinetics (doses ranged } \\
\text { from } 0.5 \mathrm{~g} \text { q8h to } 2 \mathrm{~g} \text { q4h) }\end{array}$ \\
\hline Lorente (2006) Spain [24] & MS & Cohort & $\begin{array}{l}\text { VAP with gram-negative } \\
\text { bacilli }\end{array}$ & 15 & & Meropenem & $1 \mathrm{~g}$ q6h (0.5-h infusion) & $\begin{array}{l}\mathrm{LD}, 1 \mathrm{~g} \text { over } 0.5 \mathrm{~h} \text {, then } \\
1 \mathrm{~g} \text { q6h as } \mathrm{Cl}\end{array}$ \\
\hline Itabashi (2007) Japan [33] & NR & Cohort & Gram-negative pneumonia & NR & & Meropenem & $\begin{array}{l}500 \mathrm{mg} \text { q12h (0.5- to 1-h } \\
\text { infusion) }\end{array}$ & 500 mg q12 as 4-h El \\
\hline Lodise (2007) USA [25] & NR & Cohort & $\begin{array}{l}\text { Pseudomonal infections of } \\
\text { any source }\end{array}$ & 16 & & Piperacilin/tazobactam & $3.375 \mathrm{~g} \mathrm{q} 4$ or $6 \mathrm{~h}$ & $3.375 \mathrm{~g}$ q8h as 4-h El \\
\hline
\end{tabular}


Table 1 Characteristics of selected studies for meta-analysis (Continued)

\begin{tabular}{|c|c|c|c|c|c|c|c|}
\hline Lorente (2007) Spain [26] & MS & Cohort & $\begin{array}{l}\text { VAP with gram-negative } \\
\text { bacilli }\end{array}$ & 16 & Ceftazidime & $2 \mathrm{~g} \mathrm{q12h}$ (0.5-h infusion) & $\begin{array}{l}\mathrm{LD}, 1 \mathrm{~g} \text { over } 0.5 \mathrm{~h} \text {, then } \\
2 \mathrm{~g} \text { q12h as } \mathrm{Cl}\end{array}$ \\
\hline Lorente (2009) Spain [31] & MS & Cohort & $\begin{array}{l}\text { VAP with gram-negative } \\
\text { bacilli }\end{array}$ & 16 & Piperacillin/tazobactam & $4.5 \mathrm{~g}$ q6h (0.5-h infusion) & $\begin{array}{l}\mathrm{LD}, 4.5 \mathrm{~g} \text { over } 0.5 \mathrm{~h} \text {, then } \\
4.5 \mathrm{~g} \text { g6h as Cl }\end{array}$ \\
\hline Nicasio (2010) USA [27] & $M S, N$ & Cohort & VAP & 19 & Cefepime, or meropenem & MD discretion (0.5 h-infusions) $)^{a}$ & $\begin{array}{l}\text { VAP pathway derived by local } \\
\text { MICs and PD analysis using } \\
\text { Monte Carlo simulations } \\
\text { (3-h infusions) }\end{array}$ \\
\hline Dow (2011) USA [30] & MS & Cohort & Any infection except CF & 25 & $\begin{array}{l}\text { Piperacillin/tazobactam, } \\
\text { or meropenem }\end{array}$ & $\begin{array}{l}\mathrm{P} / \mathrm{T} 3.375 \mathrm{~g} \text { q6h or Meropenem } \\
500 \mathrm{mg} \text { q6h (0.5-h infusions) }\end{array}$ & $\begin{array}{l}\mathrm{P} / \mathrm{T} 3.375 \mathrm{~g} \text { q8h as } 4 \mathrm{~h} \mathrm{El,} \\
\text { Meropenem } 500 \mathrm{mg} \text { q6h } \\
\text { as 3-h El }\end{array}$ \\
\hline Yost (2011) USA [28] & NR & Cohort & Any gram-negative infection & $\sim 14^{c}$ & Piperacillin/tazobactam & $\begin{array}{l}\text { Variable nonextended infusions of } \\
\text { piperacillin/tazobactam, cefepime, } \\
\text { ceftazidime, imipenem, meropenem, } \\
\text { doripenem }\end{array}$ & $3.375 \mathrm{~g}$ q8h as 4-h El \\
\hline Akers (2012) USA [34] & Burn & Cohort & Gram-positive bacteremia & $N R$ & Vancomycin & $\begin{array}{l}1 \mathrm{~g} \text { q8h (dose adjustment to achieve } \\
\text { trough levels } 15-20 \mu \mathrm{gg} / \mathrm{ml} \text { ) }\end{array}$ & $\begin{array}{l}3 \mathrm{~g} \text { as } \mathrm{Cl} \text { (dose adjustment to } \\
\text { achieve steady-state levels } \\
20-25 \mu \mathrm{g} / \mathrm{ml} \text { ) }\end{array}$ \\
\hline Lee (2012) USA [35] & NR & Cohort & Gram-negative infections & $N R^{d}$ & Piperacillin/tazobactam & 2.25-4.5 g q6-8 h (0.5-h infusion) & $3.375 \mathrm{~g}$ q8h as 4-h El \\
\hline Arnold (2013) USA [36] & NR & Cohort & Gram-negative infections & 20 & $\begin{array}{l}\text { Cefepime, meropenem, or } \\
\text { piperacillin/tazobactam }\end{array}$ & $\begin{array}{l}\text { Cefepime } 2 \mathrm{~g} \text { q8h, meropenem } \\
1 \mathrm{~g} \text { q8h, piperacillin-tazobactam } \\
4.5 \mathrm{~g} \text { q6h (0.5-h infusions) }\end{array}$ & $\begin{array}{l}\text { Same dose/medications as } \\
\text { 3-h infusions }\end{array}$ \\
\hline Hsaiky (2013) USA [37] & NR & Cohort & Gram-negative infections & 16 & Doripenem & $0.5 \mathrm{~g}$ g8h (1-h infusion) & $0.5 \mathrm{~g}$ q8h (4-h infusion) \\
\hline
\end{tabular}

$\mathrm{M}$, mixed; MS, medical surgical; T, trauma; $\mathrm{C}$, coronary; $\mathrm{CV}$, cardiovascular; $\mathrm{N}$, neurosurgical; NR, not reported.

apiperacillin/tazobactam used as $24 \mathrm{~h}$ infusions in control group and not used in the intervention group.

bonly mean SAPS score [86] equal to 14 provided.

'Only midpoint of range provided.

'Median SOFA [87] score of 9 .

APACHE II, mean or median acute physiology and chronic health evaluation II score of enrolled patients [88]; Cl, continuous infusion; El, extended infusion; LD, loading dose; MIC, minimum inhibitory concentration; PD,

pharmacodynamic; PCK, pharmacokinetic; RCT, randomized controlled trial; SAPS II, mean or median simplified acute physiology score II score of enrolled patients [89]; SOFA, sequential organ failure assessment score [87]; VAP, pharmacodynamic, $P$ CK, phammacok 


\section{Materials and methods Data sources}

With the assistance of a librarian, we systematically searched MEDLINE, HealthStar, EMBASE, Cochrane Clinical Trials Registry, and CINAHL electronically from inception (1948, 1967, 1974, 1966, and 1981, respectively) to September 24, 2013, by using the following key words: critical care, critical illness, intensive care unit, specific names of antibacterial agents, pharmacokinetic, pharmacodynamic, extended infusion, continuous infusion, drug administration, and dual individualization. Terms were "exploded" and combined by using Boolean operators where appropriate [see Additional file 1]. No language restrictions were applied. Reference lists of selected articles and personal files were also searched for relevant citations.

\section{Study selection}

Inclusion criteria for this meta-analysis were as follows: (a) adult (older than 16 years) critically ill patients, (b) intervention that compared PDD to aid in the determination of antibiotic dosage (that is, extended infusions, continuous infusions, clinical pathway, and dual individualization principle) with a control group that did not use such dosing strategies by using either a randomized or nonrandomized study design; (c) reporting of any patient outcomes (for example, mortality, length of stay, clinical failure); and (d) any antibacterial whose PD associated with optimal killing is the proportion of time during dosing interval that is above the MIC of the pathogenic organism. Studies were excluded if (a) $<50 \%$ of patients were admitted to an ICU defined by authors; (b) $<50 \%$ adult patients; (c) only Monte Carlo simulation or mathematical modeling data were included; (d) no clinical outcomes were reported; (e) data were published only as an abstract; or (f) different antibiotics were used in the control/intervention groups. Citations were screened in duplicate from the initial results of the search strategy, while full-text review, also in duplicate, was performed to determine eligibility when either screening reviewer thought a citation potentially met inclusion criteria. Disagreements regarding inclusion were reconciled by consensus.

\section{Data extraction}

A standardized data-abstraction form was designed before the conduct of the literature search. Two reviewers (CC, JF) independently abstracted data from included studies, including data on the publication (that is, year, author, and country), type of ICU, patient population, study design, interventions used (that is, antibiotic used, method of dosing), and outcomes (that is, mortality, ICU and hospital LOS, clinical failure rates). No data on

Table 2 Quality assessment of included randomized controlled trials

\begin{tabular}{|c|c|c|c|c|c|c|c|}
\hline $\begin{array}{l}\text { Author (year) } \\
\text { Country }\end{array}$ & $\begin{array}{l}\text { Number of } \\
\text { centres }\end{array}$ & $\begin{array}{l}\text { Number of } \\
\text { patients }\end{array}$ & Blinding & $\begin{array}{l}\text { concealed } \\
\text { allocation }\end{array}$ & $\begin{array}{l}\text { Intention-to-treat } \\
\text { analysis }\end{array}$ & $\begin{array}{l}\text { Stopped early } \\
\text { for benefit }\end{array}$ & $\begin{array}{l}\text { Post randomization } \\
\text { Withdrawal }\end{array}$ \\
\hline Georges (1999) France [12] & 1 & 18 & $\mathrm{~N}$ & NR & $N R$ & $\mathrm{~N}$ & $N R$ \\
\hline Hanes (2000) USA [13] & 1 & 32 & $\mathrm{~N}$ & $N R$ & NR & $\mathrm{N}$ & Y (1 from each group) \\
\hline Nicolau (2001) USA [14] & 1 & 41 & N & $N R$ & NR & N & $\begin{array}{l}\text { Y (5 from Cl group and } \\
1 \text { from control group) }\end{array}$ \\
\hline Wysocki (2001) France [15] & 10 & 160 & N & $\begin{array}{l}\text { Y (consecutive } \\
\text { sealed opaque } \\
\text { envelopes) }\end{array}$ & Y & $\mathrm{N}$ & $\begin{array}{l}\text { Y (15 from Cl and } 26 \text { from } \\
\text { control group) }\end{array}$ \\
\hline Bujik (2002) Netherlands [16] $]^{a}$ & 1 & 18 & $\mathrm{~N}$ & $N R$ & NR & $\mathrm{N}$ & $N R$ \\
\hline Georges (2005) France [17] & 1 & 50 & N & $N R$ & NR & $\mathrm{N}$ & $N R$ \\
\hline Rafati (2006) Iran [18] & 1 & 40 & $\mathrm{~N}$ & NR & $\mathrm{NR}$ & $\mathrm{N}$ & $N R$ \\
\hline Roberts (2007) Australia [19] & 1 & 57 & $\mathrm{~N}$ & $\begin{array}{l}\text { Y (sequential opaque } \\
\text { sealed envelopes) }\end{array}$ & Y & $\mathrm{N}$ & $N$ \\
\hline Sakka (2007) Germany [20] & 1 & 20 & $N$ & Y (sealed envelopes) & $N R$ & $\mathrm{~N}$ & $N R$ \\
\hline Adembri (2008) Italy [21] & 1 & 16 & $N$ & Y (closed envelopes) & NR & $\mathrm{N}$ & $\begin{array}{l}\text { Y (1 died, } 1 \text { developed ARF; } \\
\text { group(s) not specified) }\end{array}$ \\
\hline Wang (2009) China [32] & 1 & 30 & N & NR & NR & $\mathrm{N}$ & $N R$ \\
\hline Chyta (2012) Czech [22] & 1 & 240 & $N$ & $\begin{array}{l}\text { Y (sealed opaque } \\
\text { envelopes) }\end{array}$ & Y & $\mathrm{N}$ & $\begin{array}{l}\mathrm{N} \text { for mortality and LoS, but } \\
\text { Y (14 in Cl and, } 12 \text { in control } \\
\text { group) for cure data }\end{array}$ \\
\hline $\begin{array}{l}\text { Dulhunty (2012) } \\
\text { Australia [29] }\end{array}$ & 5 & 60 & Y & $\begin{array}{l}\text { Y (sequentially } \\
\text { numbered sealed } \\
\text { envelopes) }\end{array}$ & Y & $\mathrm{N}$ & $\mathrm{N}$ \\
\hline
\end{tabular}

Y, Yes; N, No; NR, not reported; Cl, continuous infusion; LoS, length of stay; ARF, acute renal failure.

a Partial randomization: first six patients allocated to continuous-infusion group; next 12 patients randomized to continuous infusion or intermittent administration groups. 
harm (for example, superinfection, resistance rates) were extracted because very few studies reported such data. Risk of bias in RCTs (including blinding of participants, method of sequence generation and allocation concealment, intention-to-treat analysis, early trial stopping for efficacy before the planned enrollment was completed, and loss to follow up) and cohort studies (including retrospective versus prospective data collection, concurrent versus historical controls, and comparable baseline characteristics of cases and controls) were assessed, with disagreements resolved by consensus.

\section{Data analysis}

Our primary outcome was all-cause mortality in patients whose infections were managed with PDD (intervention group) as compared with those whose infections were managed by antibiotic dosing that did not incorporate both pharmacodynamic and pharmacokinetic information (control group). Mortality was determined at ICU discharge, hospital discharge, $90,60,30,28$, or 14 days after study enrolment (in descending order of preference). Secondary outcomes were ICU and hospital LOS, and clinical failure as defined by individual study authors (for example, lack of clinical cure or improvement). Separate analyses were performed by using lack of clinical cure alone. Only RCTs were included in the primary analysis, and prespecified subgroup analyses were as follows: (a) by type of study (that is, RCT and cohort studies); (b) by antibiotic type (for example, beta-lactam alone, carbapenem alone, cephalosporin alone, piperacillin/tazobactam alone, or others); and (c) by intervention (that is, extended infusions and continuous infusions). All analyses were performed by using Review Manager (RevMan version 5.2; Cochrane Collaboration, Oxford, UK) and random effects models, which incorporate between-trial heterogeneity and give wider and more conservative confidence intervals (CIs) when heterogeneity is present [8].

We assessed statistical heterogeneity among trials by using $I^{2}$, defined as the percentage of total variability across studies attributable to heterogeneity rather than

Table 3 Quality assessment of included cohort studies

\begin{tabular}{|c|c|c|c|c|c|}
\hline Author (year) Country & $\begin{array}{l}\text { Number of } \\
\text { centers }\end{array}$ & $\begin{array}{l}\text { Number of } \\
\text { patients }\end{array}$ & $\begin{array}{l}\text { Prospective/ } \\
\text { retrospective }\end{array}$ & Concurrent control & Comparable baseline \\
\hline Schentag (1984) USA [23] & 1 & 32 & Prospective & N (historical) & $N R$ \\
\hline Lorente (2006) Spain [24] & 1 & 89 & Retrospective & Y (physician discretion) & Y \\
\hline Itabashi (2007) Japan [33] & 1 & 42 & Prospective & Y (physician discretion) & Y \\
\hline Lodise (2007) USA [25] & 1 & 194 & Retrospective & N (historical) & Y \\
\hline Lorente (2007) Spain [26] & 1 & 121 & Retrospective & Y (physician discretion) & Y \\
\hline Lorente (2009) Spain [31] & 1 & 83 & Retrospective & Y (physician discretion) & Y \\
\hline Nicasio (2010) USA [27] & 1 (3 separate ICUs) & 168 & Prospective & N (historical) & $\begin{array}{l}\text { Y (except fewer intervention } \\
\text { patients with liver disease) }\end{array}$ \\
\hline Dow (2011) USA [30] & 1 & 121 & Retrospective & N (historical) & Y \\
\hline Yost (2011) USA [28] & 14 & 359 & Retrospective & Y (physician discretion) & $\begin{array}{l}\mathrm{N} \text { (higher use of concomitant } \\
\text { aminoglycosides, pseudomonas } \\
\text { infections, and rates of positive } \\
\text { cultures from respiratory and } \\
\text { other sources in control patients) }\end{array}$ \\
\hline Akers (2012) USA [34] & 1 & 171 & Retrospective & Y (physician discretion) & $\begin{array}{l}\text { Y (except control group received } \sim 10 \% \\
\text { lower average dose) }\end{array}$ \\
\hline Lee (2012) USA [35] & 2 & 148 & Retrospective & N (historical) & $\begin{array}{l}\text { Y (except control group more } \\
\text { COPD patients, more concomitant } \\
\text { use of fluoroquinolones and } \\
\text { aminoglycosides, and longer } \\
(\sim 1 \text { d) duration and higher }(\sim 13 \%) \\
\text { cumulative dose of therapy) }\end{array}$ \\
\hline Arnold (2013) USA [36] & 1 & 503 & Prospective & N (historical) & $\begin{array}{l}\text { Y (except control group more COPD } \\
\text { patients, more endotracheal (versus } \\
\text { bronchoalveolar lavage) cultures, less } \\
\text { Hemophilus influenzae, and more } \\
\text { use of meropenem) }\end{array}$ \\
\hline Hsaiky (2013) USA [37] & 1 & $86^{a}$ & Retrospective & N (historical) & $\begin{array}{l}\text { Y (except control group had lower } \\
\text { proportion of patients with positive } \\
\text { blood cultures) }\end{array}$ \\
\hline
\end{tabular}


chance, and used published guidelines for low $\left(I^{2}=25 \%\right.$ to $49 \%)$, moderate $\left(I^{2}=50 \%\right.$ to $\left.74 \%\right)$, and high $\left(I^{2} \geq 75 \%\right)$ heterogeneity [9]. Relative risks (RRs) were used to pool binary mortality and clinical failure data, and weighted mean differences (MDs) to pool continuous LOS data. Ranges [10] and interquartile ranges [11] were converted to standard deviations by using previously published methods where necessary. Differences between pooled RRs were evaluated by using z tests. We considered (two-sided) $P \leq$ 0.05 as significant and reported individual trial and summary results with $95 \%$ confidence intervals. To assess for publication bias, we visually examined a funnel plot comparing effect measure for the primary outcome of mortality with study precision for evidence of asymmetry.

\section{Results}

\section{Study selection}

In total, 26 studies were included in this meta-analysis [12-37]. The initial search strategy resulted in 1,319 citations, of which 69 were retrieved for full review and 21 met all inclusion criteria and no exclusion criteria [12-28,34-37]. Review of reference lists of the selected studies, other systematic reviews [5-7], and personal files resulted in five additional studies being included [29-33] (Figure 1). The majority of studies were excluded during initial screening because they were Monte Carlo simulation studies that did not involve patients, or were studies that did not involve PDD. The 48 studies were excluded after full review for the following reasons: lack of control group or clinical outcomes [38-64], not discussing pharmacodynamic-based dosing [65-74], Monte Carlo simulations or mathematical modeling [75-81], duplicate publications $[82,83]$, and review articles $[84,85]$.

\section{Description of included studies}

The characteristics of the studies included in the metaanalysis are described in Table 1 . The included studies are international (Europe, 10, USA, 11, Asia, 3, Australia, 2)

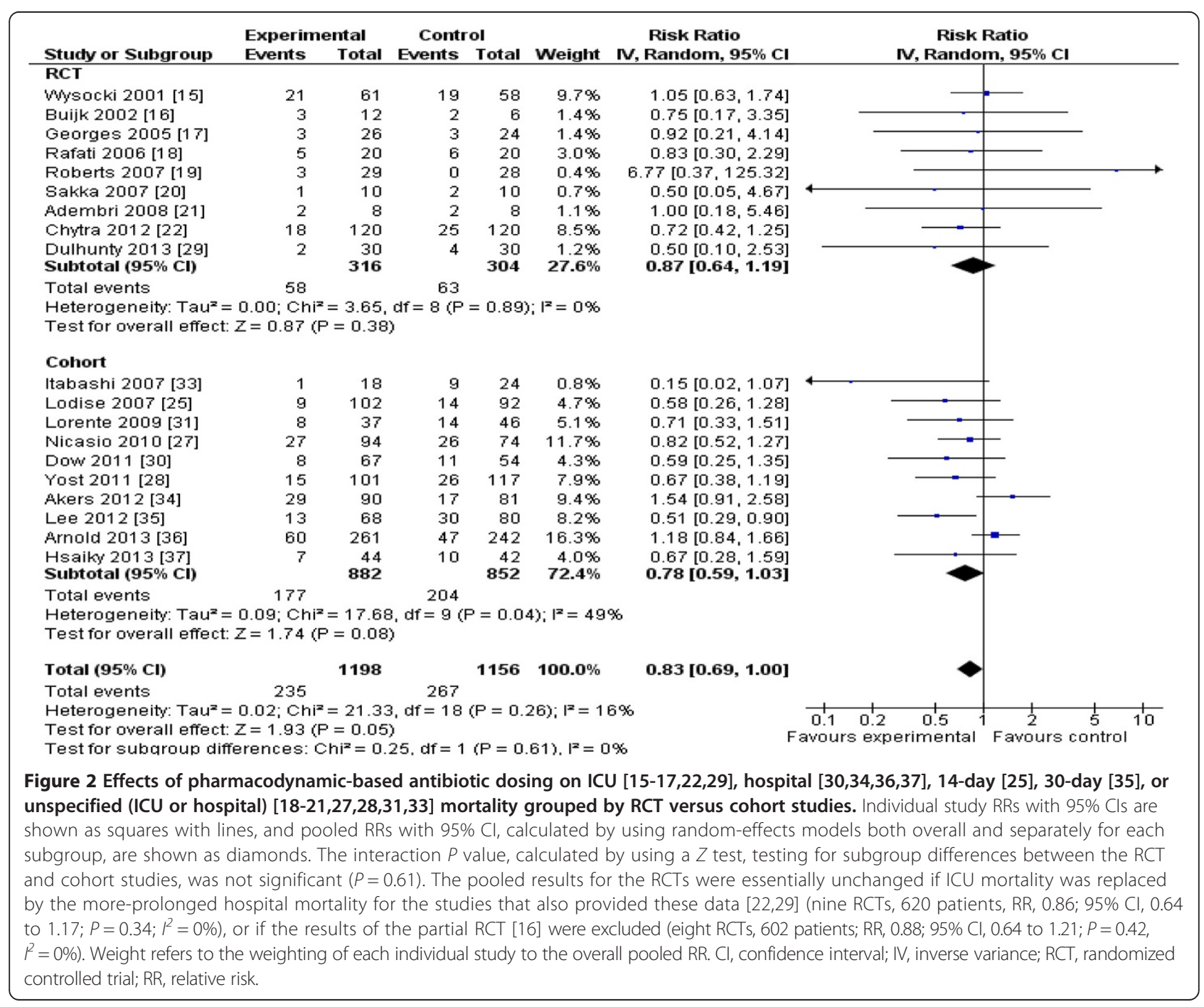


with a variety of ICU patients (for example, medical, surgical, trauma, mixed) diagnosed mainly with pneumonia $(n$ $=12)$. Most studies involved a single antibiotic $(n=22)$, typically with beta-lactam $(n=13)$ or carbapenem class $(n$ $=6)$ or both $(n=4)$. Most used either continuous $(n=16)$ or extended $(n=8)$ infusion interventions, whereas one was a clinical pathway designed by using local antibiogram and MIC information and another by using the dualindividualization principle. Thirteen studies were RCTs, and 13 were cohort studies, of which four were prospective, and nine, retrospective. All but two of the RCTs and all but two of the non-RCTs were single center. Sample size ranged from 16 to 240 patients for the RCTs and 32 to 503 for the cohort studies.

For the 13 RCTs, only one had the participants blinded to study interventions, whereas six reported allocation concealment, and four specified that analysis was by intention-to-treat. Only three of the RCTs specifically reported that losses to follow-up were $<5 \%$ of randomized patients.
For the cohort studies, only four of the 13 were prospective, and six studies used concurrent control groups. Details regarding assessment of bias among individual studies are outlined in Tables 2 and 3.

\section{Morbidity and mortality}

The 13 RCTs [12-22,29,32] included data from 782 patients, and the 13 cohort studies [23-28,30,31,33-37], from 2,117 patients. Two studies [28,37] enrolling all hospitalized patients reported mortality data separately for patients requiring ICU admission. Reduction in mortality (nine RCTs; $n=620$; RR, $0.87 ; 95 \% \mathrm{CI}, 0.64$ to 1.19 ; $P=0.38$ ) almost achieved statistical significance when the results of all included studies (RCTs and cohort studies) were pooled (19 studies; $\mathrm{n}=2,354 ; \mathrm{RR}, 0.83$; $95 \%$ CI, 0.69 to $1.00 ; P=0.054$ ) (Figure 2). Focusing the pooled analysis on only RCTs, PDD significantly reduced clinical failure rates, defined as either lack of clinical cure or improvement (seven RCTs; $n=565$; RR, 0.68; 95\% confidence interval $[\mathrm{CI}], 0.49$ to $0.94 ; P=0.02$ )

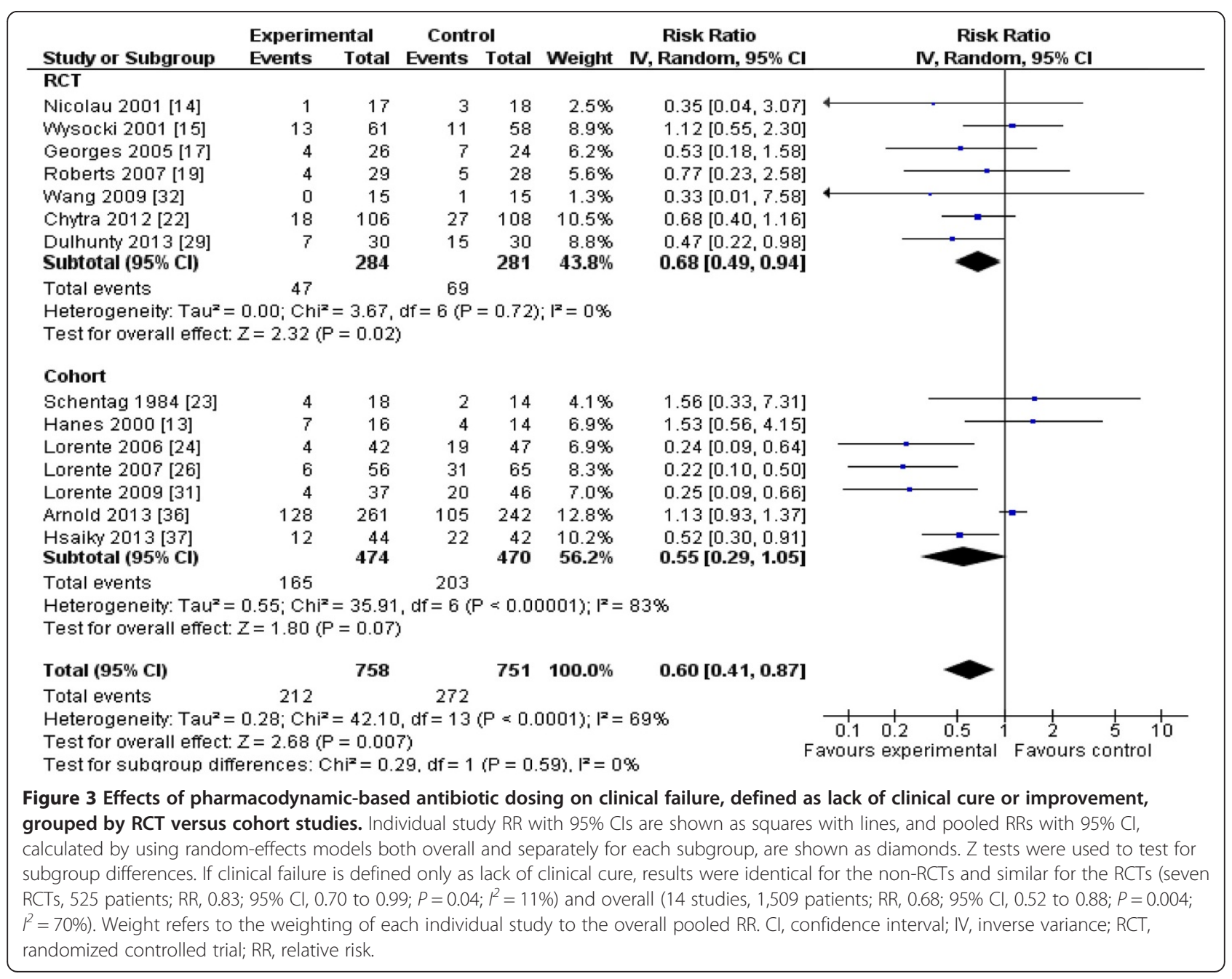


(Figure 3), and ICU LOS (five RCTs; $n=442$; mean difference, $-1.5 ; 95 \% \mathrm{CI},-2.8$ to -0.2 days; $P=0.02$ ) (Figure 4 ). There was no significant between-trial heterogeneity for these analyses $\left(I^{2}=0\right)$. Incorporating pooled data from non-RCTs also yielded significantly reduced clinical failure rates but with increased heterogeneity (Figure 3). PDD did not result in reduced hospital lengths of stay, but few studies reported this outcome (Figure 5). Visual inspection of the funnel plot comparing the effect measure (RR) for the primary outcome of mortality for each study with its precision, expressed as the standard error of the natural logarithm of RR, $\mathrm{SE}(\log (\mathrm{RR}))$ did not suggest asymmetry (see Additional file 2).

\section{Subgroup analysis}

Examining effects by types of antibiotics (Figure 6), only studies involving piperacillin/tazobactam (or piperacillin alone) clearly demonstrated a survival advantage for the intervention group (five studies [18,25,28,31,35], $n=683$; RR, $0.62 ; 95 \%$ CI, 0.46 to $0.85 ; P=0.003 ; I^{2}=0 \%$ ), although only one of five studies in this subgroup was an RCT [18]. Studies involving carbapenems almost demonstrated a survival advantage for the intervention group (four trials $[20,22,33,37] ; n=388$; RR, $0.64 ; 95 \% \mathrm{CI}, 0.41$ to 1.00 ; $\left.P=0.051 ; I^{2}=0 \%\right)$, with two of four studies being RCTs $[20,22]$. With respect to type of intervention, extended infusions, all of which were cohort studies, improved survival (eight studies [25,27,28,30,33,35-37]; $n=1,580$; RR, 0.72 ; $95 \% \mathrm{CI}, 0.54$ to $0.96 ; P=0.03 ; I^{2}=42 \%$ ). Improved survival in the studies using continuous infusions did not achieve statistical significance (nine RCTs [15-22,29] and two cohort studies [31,34], $n=874$; RR, 0.97; 95\% CI, 0.76 to $1.25 ; P=0.84 ; I^{2}=0$ ) (Figure 7 ).

\section{Discussion}

Pooled results from small RCTs suggest that PDD, by using primarily continuous or extended infusions of antibiotics, reduces clinical failure rates and ICU LOS in critically ill patients when compared with traditional dosing methods. Reduced mortality rates almost achieved statistical significance when the results of RCTs were combined with cohort studies.

Unlike previous meta-analyses, our systematic review included only data from critically ill patients, stratified

\begin{tabular}{|c|c|c|c|c|c|c|c|c|c|}
\hline \multirow[b]{2}{*}{ Study or Subgroup } & \multicolumn{3}{|c|}{ Experimental } & \multicolumn{3}{|c|}{ Control } & \multirow[b]{2}{*}{ Weight } & \multirow{2}{*}{$\begin{array}{l}\text { Mean Difference } \\
\text { N, Random, } 95 \% \mathrm{Cl}\end{array}$} & \multirow{2}{*}{$\begin{array}{l}\text { Mean Difference } \\
\text { IN, Random, } 95 \% \mathrm{Cl}\end{array}$} \\
\hline & Mean & SD & Total & Mean & SD & Total & & & \\
\hline \multicolumn{10}{|c|}{ 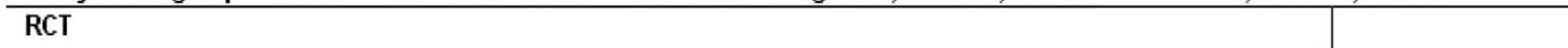 } \\
\hline Nicolau 2001 [14] & 8.5 & 3.4 & 17 & 9.3 & 4 & 18 & $13.4 \%$ & $-0.80[-3.25,1.65]$ & | \\
\hline Georges 2005 [17] & 34 & 17 & 26 & 40 & 15 & 24 & $2.9 \%$ & $-6.00[-14.87,2.87]$ & \\
\hline Roberts 2007 [19] & 10.8 & 23.2 & 29 & 5.6 & 6 & 28 & $2.9 \%$ & $5.20[-3.53,13.93]$ & \\
\hline Chytra 2012 [22] & 10 & 5.19 & 120 & 12 & 8.89 & 120 & $15.5 \%$ & $-2.00[-3.84,-0.16]$ & \\
\hline Dulhunty 2013 [29] & 7.5 & 5.93 & 30 & 9 & 6.85 & 30 & $10.9 \%$ & $-1.50[-4.74,1.74]$ & \\
\hline Subtotal $(95 \% \mathrm{Cl})$ & & & 222 & & & 220 & $45.7 \%$ & $-1.50[-2.81,-0.19]$ & \\
\hline \multicolumn{10}{|c|}{$\begin{array}{l}\text { Heterogeneity: } \operatorname{Tau}^{2}=0.00 ; \mathrm{Chi}^{2}=3.85, \mathrm{df}=4(\mathrm{P}=0.43) ; \mathrm{l}^{2}=0 \% \\
\text { Test for overall effect: } Z=2.24(\mathrm{P}=0.02)\end{array}$} \\
\hline \multicolumn{10}{|l|}{ Cohort } \\
\hline Hanes 2000 [13] & 26.8 & 20.1 & 16 & 15.5 & 5.9 & 14 & $2.2 \%$ & $11.30[0.98,21.62]$ & \\
\hline Lorente 2009 [31] & 21.81 & 12.34 & 37 & 25.61 & 19.84 & 46 & $4.2 \%$ & $-3.80[-10.78,3.18]$ & \\
\hline Nicasio 2010 [27] & 20.2 & 15.9 & 94 & 24.6 & 19 & 74 & $6.2 \%$ & $-4.40[-9.79,0.99]$ & \\
\hline Dow 2011 [30] & 10.7 & 9.6 & 67 & 15.3 & 9.6 & 54 & $10.4 \%$ & $-4.60[-8.04,-1.16]$ & \\
\hline Lee 2012 [35] & 5 & 7.41 & 68 & 5 & 3.7 & 80 & $15.2 \%$ & $0.00[-1.94,1.94]$ & \\
\hline Arnold 2013 [36] & 10.8 & 8.9 & 261 & 9.3 & 10.1 & 242 & $16.1 \%$ & $1.50[-0.17,3.17]$ & \\
\hline Subtotal $(95 \% \mathrm{Cl})$ & & & 543 & & & 510 & $54.3 \%$ & $-0.86[-3.60,1.88]$ & \\
\hline \multicolumn{10}{|c|}{$\begin{array}{l}\text { Heterogeneity: } \operatorname{Tau}^{2}=6.85 ; \mathrm{Chi}^{2}=18.27, \mathrm{df}=5(\mathrm{P}=0.003) ; \mathrm{I}^{2}=73 \% \\
\text { Test for overall effect: } Z=0.61(P=0.54)\end{array}$} \\
\hline \multirow{2}{*}{\multicolumn{8}{|c|}{$\begin{array}{l}\text { Total }(\mathbf{9 5} \% \mathrm{Cl}) \quad \mathbf{7 6 5} \quad \mathbf{7 3 0} \quad \mathbf{1 0 0 . 0} \% \\
\text { Heterogeneity: } \text { Tau }^{2}=3.54 ; \mathrm{Ch}^{2}=25.12, \mathrm{df}=10(\mathrm{P}=0.005) ; \mathrm{I}^{2}=60 \% \\
\text { Test for overall effect: } Z=1.23(\mathrm{P}=0.22) \\
\text { Test for subqroup differences: } \mathrm{Chi}^{2}=0.17, \mathrm{df}=1(\mathrm{P}=0.68), \mathrm{I}^{2}=0 \%\end{array}$}} & $-1.02[-2.65,0.60]$ & \\
\hline & & & & & & & & & $\begin{array}{ccccc}1 & 1 & & 1 & 1 \\
-10 & -5 & 0 & 5 & 10 \\
\text { Favours experimental } & \text { Favours control }\end{array}$ \\
\hline \multicolumn{10}{|c|}{$\begin{array}{l}\text { Figure } 4 \text { Effects of pharmacodynamic-based antibiotic dosing on ICU length of stay, grouped by RCT versus cohort studies. Individual } \\
\text { study RRS with } 95 \% \text { Cls are shown as squares with lines, and pooled RRs with } 95 \% \text { CI, calculated by using random-effects models both overall } \\
\text { and separately for each subgroup, are shown as diamonds. Z tests were used to test for subgroup differences. IQR [22,29,35,36] converted to } \\
\text { standard deviations by dividing by 1.35, as previously described [11], or standard deviations calculated from reported 95\% Cls, assuming equal } \\
\text { standard deviations between groups [30]. Weight refers to the weighting of each individual study to the overall pooled RR. CI, confidence interval } \\
\text { IV, inverse variance; RCT, randomized controlled trial; SD, standard deviation; IQR, interquartile range. }\end{array}$} \\
\hline
\end{tabular}




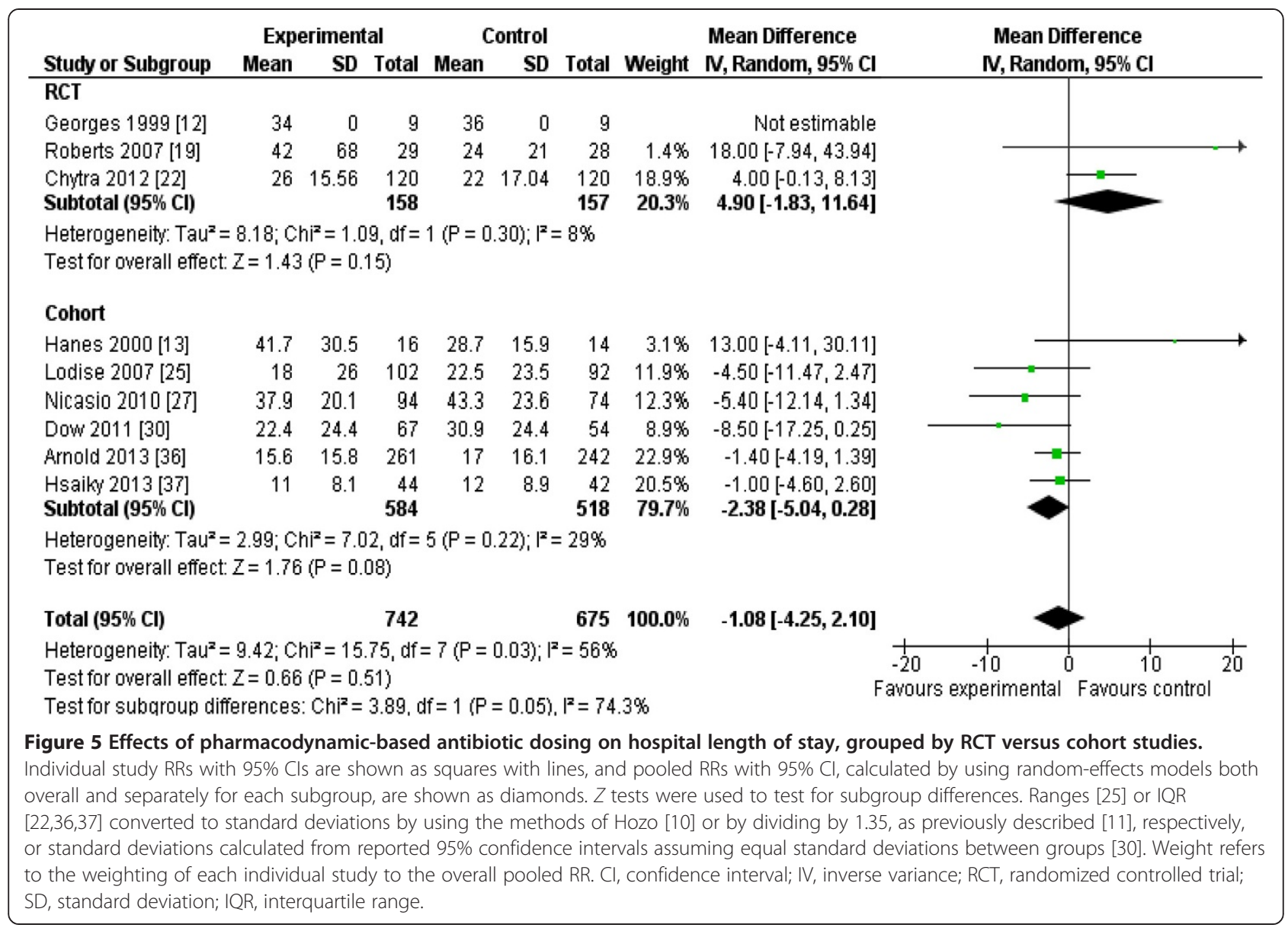

results by RCTs versus cohort studies, included all clinically used antibacterial agents, and a larger number of studies. We were able to demonstrate a statistically significant improvement in clinical outcomes (reduced clinical failure rates) and ICU LOS, even when exclusively methodologically more-rigorous RCT data are pooled. Three previous meta-analyses, each with fewer studies, included both critically ill and non-critically ill patients and found somewhat different results. Two of these meta-analyses found either no benefit $[5,6]$ or that clinical outcomes were improved only when the same dose of antibiotic was given as continuous infusions when compared with intermittent infusions [6]. Our more comprehensive and updated search included all of the RCTs in ICU found in previous systematic reviews plus additional studies, which may have contributed to these differences.

Similar to the most recent meta-analysis [7], we also found that mortality improvement was seen with continuous/extended infusions of only piperacillin/tazobactam and carbapenems in ICU patients, albeit largely because of data from non-RCTs.

Our pooled results, at least among RCTs, were consistent between studies. This lack of statistical heterogeneity occurred despite significant differences between studies in types of antibiotics used, interventions studied (that is, extended or continuous infusions, or other pharmacodynamicbased dosing strategies), dosages of antibiotic used (that is, whether both arms of the study received the same dose of antibiotic, whether loading doses were given), types of organisms or infections studied, and whether concomitant pharmacokinetic data (that is, therapeutic drug monitoring) was also performed to validate the dosing strategies. We found piperacillin/tazobactam to be the most studied antibiotic, and the only one that resulted in a clear improvement in mortality, albeit largely because of cohort studies. In our study, extended infusions but not continuous infusions demonstrated a statistically significant reduction in mortality. This is inconsistent with the theoretical background, given that extended infusions may not result in serum antibiotic concentrations that are above the minimum inhibitory concentration (MIC) of the infecting pathogen throughout the entire dosing interval, and our findings may be due to methodologic differences, given that all of the extended-infusion studies were nonrandomized, whereas all but two of the continuousinfusion studies were RCTs. However, although for antibiotics such as beta-lactams and carbapenems, the 


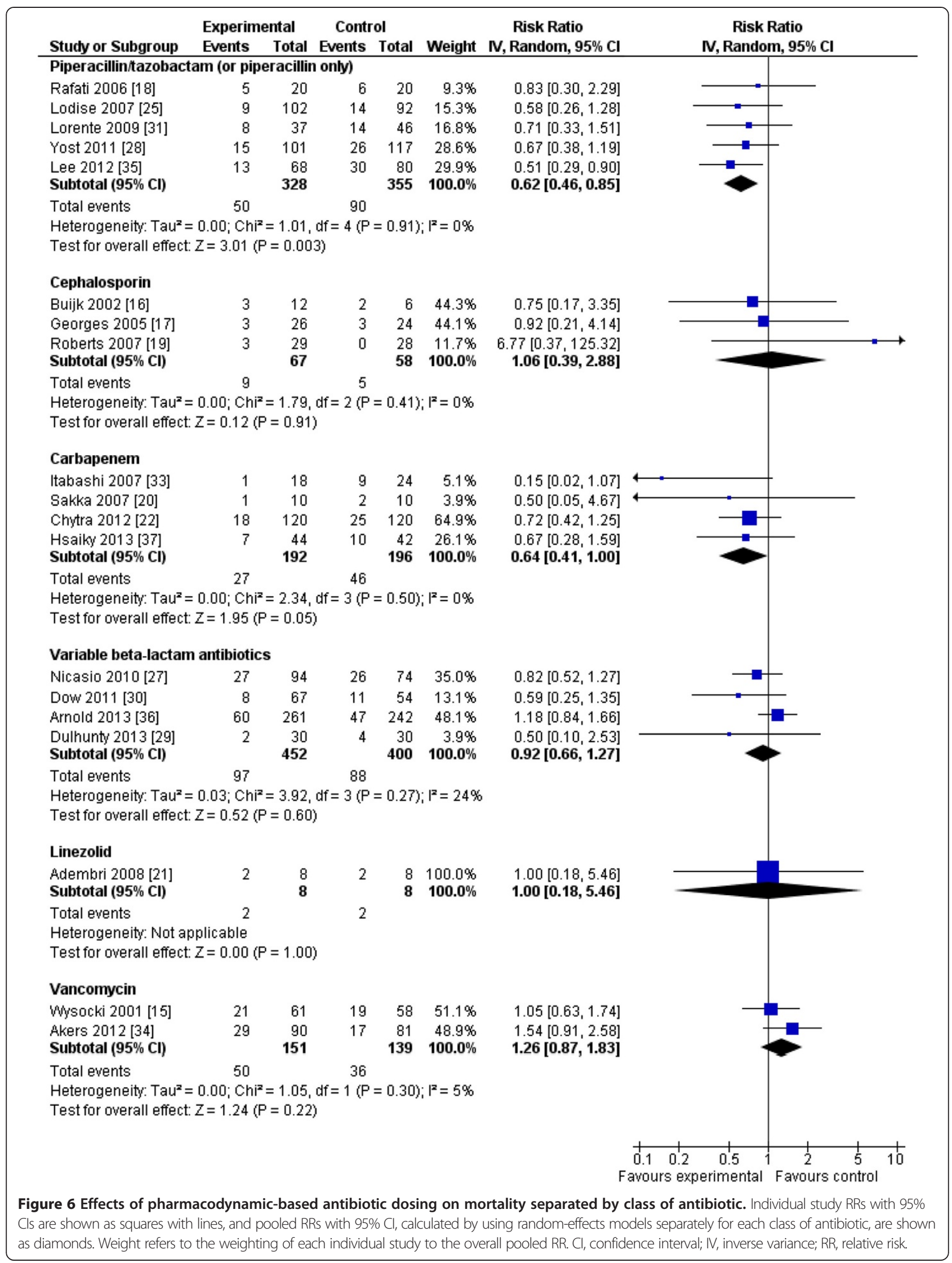


commonly accepted PD parameter associated with improved cure rates are free drug concentration above MIC for $40 \%$ to $70 \%$ of the dosing interval, these parameters have not been subjected to rigorous clinical evaluation in multiple studies, and their validity was recently challenged [90].

In addition, it is well known that pharmacokinetic parameters are highly variable in critically ill patients because of a variety of factors [91], and thus whether any PD targets were actually attained by any interventions should ideally be confirmed by using actual pharmacokinetic measurements in each individual study, to better correlate with clinical and other end points. For example, augmented renal clearance, seen in some critically ill sepsis and trauma patients [92], might lead to an inability to achieve concentrations above the MIC because of greater clearance in some patients, and this would have a greater impact on continuous versus extended infusions.

As evident from the list of studies included in this meta-analysis, PDD strategies are not a new concept. Indeed, the concept of dual-individualization incorporating both patient PCK and bacterial PD information to arrive at dosage regimen dates back to the 1980s [23]. Even the concept of extended or continuous infusions would benefit from individualization by using patient-specific PCK parameters and organism-specific MIC to verify that these infusions did indeed reach the PD target. Given the intense resources required for such an intervention (that is, infrequently reported PCK of antibiotics in ICU patients, or bacteria-specific MIC for each infection), this concept has not been universally adopted.

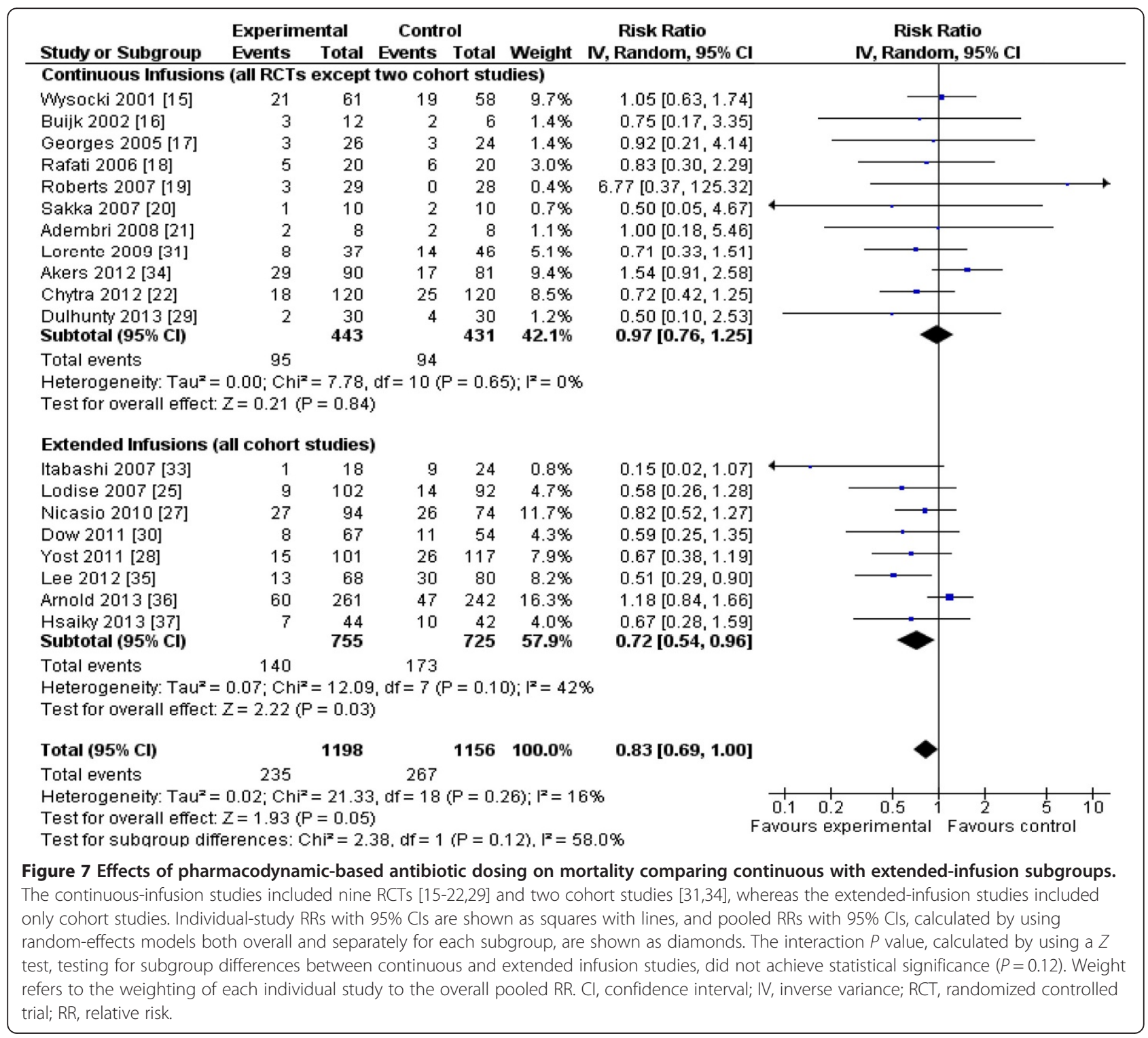


More recently, given the increase in bacterial resistance and dearth of new antibiotics, significant attention has been paid to optimizing use of currently existing antibiotics through, for example, extended/continuous infusions. Practically speaking, it is still not an accepted standard of practice for all institutions to report MICs for all organisms despite having these MICs determined by automated systems because of errors associated with automated techniques, and there are still a large number of unknowns when it comes to PCK parameters in ICU patients. Therefore to translate the knowledge truly from the plethora of in vitro / Monte Carlo-type studies to actual ICU patients, significant system changes and further research, as previously outlined, must occur. This systematic review of primarily small, single-center studies of critically ill patients, a patient population that is most likely to benefit because of their severity of illness and increased potential for infections with more-resistant organisms, suggests that PDD may lead to improved patient-centered clinical outcomes and supports the conduct of more adequately powered and rigorously performed RCTs to confirm these findings.

The strengths of our study include the use of rigorous systematic review and meta-analytic methods consistent with PRISMA guidelines [93], including a reproducible and comprehensive literature-search strategy without language restrictions, clearly defined inclusion criteria, duplicate citation review, data abstraction, and quality assessment of individual studies, and a predefined statistical-analysis plan. Our meta-analysis also included more studies of critically ill patients: previous metaanalyses included only five to seven studies enrolling primarily critically ill patients, of which only two to six were RCTs [5-7], whereas our meta-analysis included 26 studies enrolling primarily critically ill patients, of which 13 were RCTs.

Our study also has limitations. The numbers of patients enrolled in the selected studies were relatively small, and most of the RCTs were unblinded and single center, with only a minority reporting on quality indicators, such as allocation concealment, intention-to-treat analysis, and losses to follow-up after randomization. This makes further subgroup analysis not useful, given the small sample size in each study and the types of studies. To be comprehensive, we included all antibacterials, all study types, and all dosages of antibiotics and also studies targeting different PD end points, which resulted in clinical heterogeneity among included studies. Surprisingly, the pooled results, at least among RCTs, demonstrated no statistical heterogeneity; however, tests for heterogeneity have lower statistical power when the number of trials is small. Clinical cure is a subjective outcome that was defined by each study's authors, and potentially subject to bias, given that the studies were mainly unblinded [94], and the microbiologic causes of infections were different, and appropriateness of empiric antibiotics, a key determinant of outcomes, was not reported. Even a moderately sized additional RCT could negate the statistically significant improvement in this outcome. For example, a recently completed blinded placebo-controlled RCT in critically ill patients with ventilator-associated pneumonia [95], which did not meet our inclusion criteria because it compared two different antibiotics for different durations of therapy (extended (4-hour) dose doripenem for 7 days versus intermittent dose imipenem/cilastatin for 10 days), found higher clinical failure rates in the extended-dose doripenem group (43/79 (54\%) versus 38/88 (43\%)). Adding data from this trial to our pooled result would make the improved clinical failure rates among the continuous/extended RCTs no longer statistically significant: eight RCTs, $n=732$; RR, $0.81 ; 95 \%$ CI, 0.57 to 1.15 ; $P=0.24$. It would also eliminate statistically significant mortality improvements in the subgroup of extended-infusion cohort studies, and the subgroup of carbapenem studies.

In addition, almost all studies included in this review permitted the use of concomitant antibiotics [12,14-19,21,22,24-31,34-37], whereas the remainder did not specifically report on whether their use was permitted [13,20,23,32,33]. This use of concomitant antibiotics may have contributed to reduced differences in outcomes between groups. We also did not conduct our analysis controlling for differences in antibacterial dosing regimens (for example, with or without loading doses) or patient severity of illness. The latter would require patient-level data that would be challenging to acquire.

\section{Conclusions}

In conclusion, pooled results from small RCTs suggest that PDD reduces clinical failure rates and ICU LOS in critically ill patients, and may reduce mortality rates when the results of RCTs are combined with cohort studies. Given the limitations of our review, these findings support the conduct of future adequately powered and well-designed RCTs to confirm these findings for this important clinical question.

\section{Key messages}

- Pooled analysis of randomized controlled trials suggests that continuous/extended infusions of antibiotics in critically ill patients improve cure rates, length of stay, and possibly mortality.

- This study adds to the current body of literature by focusing on critically ill patients and including a larger number of studies without restriction on type of antibiotics. 


\section{Additional files}

Additional file 1: Search Strategy. Description: Detailed search strategy used to identify relevant citations in the MEDLINE database. Similar search strategies were used for the other databases.

Additional file 2: Funnel plot. Description: Funnel plot comparing the effect measure, relative risk (RR), for the primary outcome of mortality for each study, including both randomized controlled trials and cohort

studies, with its precision, expressed as the standard error of the natural logarithm of RR, SE(log(RR)).

\section{Abbreviations}

Cl: Confidence interval; ICU: Intensive care unit; LOS: Length-of-stay; MIC: Minimum inhibitory concentration; PCK: Pharmacokinetic; PD: Pharmacodynamic; PDD: Pharmacodynamic-based dosing; $\mathrm{RCT}$ : Randomized controlled trial; RR: Relative risk.

\section{Competing interests}

On behalf of all authors, the corresponding author states that there is no competing interest.

\section{Authors' contributions}

CC contributed to the design of the study, data collection, data analysis, and wrote the initial draft of the manuscript and revised subsequent drafts. AL contributed to data collection and analysis and contributed to the draft of manuscripts. JF contributed to the design of the study, data collection and analysis, and also to the revisions of the manuscripts. All authors approved the final draft of the manuscript.

\section{Acknowledgements}

We thank David Lightfoot for his assistance with executing the original and updated search in the various databases, Marina Simms for her efforts in retrieving foreign-language articles, Jyeon Lee and Tadahiro Kobayashi for their assistance in translation from Japanese, and Mae Yuen, Dania Edgar, and Crane Wu for their assistance in study selection or in data acquisition. All work was performed at St. Michael's Hospital. No funding was associated with the study. Jan Friedrich is supported by a Clinician Scientist Award from the Canadian Institutes of Health Research.

\section{Author details}

${ }^{1}$ Pharmacy Department, St. Michael's Hospital, Toronto, Canada. ${ }^{2}$ Li Ka Shing Knowledge Institute, St. Michael's Hospital, Toronto, Canada. ${ }^{3}$ Interdepartmental Division of Critical Care, University of Toronto, Toronto, Canada. ${ }^{4}$ Critical Care and Medicine Departments, St. Michael's Hospital and University of Toronto, 30 Bond Street, Bond Wing, Room 4-015, Toronto, Ontario M5B 1W8, Canada.

Received: 3 August 2013 Accepted: 13 November 2013

Published: 29 November 2013

\section{References}

1. Boucher HW, Talbot GH, Bradley JS, Edwards JE, Gilbert D, Rice LB, Scheld M, Spellberg B, Bartlett J: Bad bugs, no drugs: no ESKAPE! An update from the Infectious Diseases Society of America. Clin Infect Dis 2009, 48:1-12.

2. Abdul-Aziz MH, Dulhunty JM, Bellomo R, Lipman J, Roberts JA: Continuous beta-lactam infusion in critically ill patients: the clinical evidence. Ann Intensive Care 2012, 2:37-53.

3. Lodise TP, Drusano GL: Pharmacokinetics and pharmacodynamics: optimal antimicrobial therapy in the intensive care unit. Crit Care Clin 2011, 27:1-18.

4. Schentag JJ, Nix DE, Adelman MH: Mathematical examination of dual individualization principles (I): relationships between AUC above MIC and area under the inhibitory curve for cefmenoxime, ciprofloxacin, and tobramycin: DICP. Ann Pharmacother 1991, 25:1050-1057.

5. Roberts JA, Webb S, Paterson D, Ho KM, Lipman J: A systematic review on clinical benefits of continuous administration of $\beta$-lactam antibiotics. Crit Care Med 2009, 37:2071-2078.

6. Kasiakou SK, Sermaides G, Michalopoulos A, Soteriades ES, Falagas ME: Continuous versus intermittent intravenous administration of antibiotics: a meta-analysis of randomised controlled trials. Lancet Infect Dis 2005, 5:581-589.
7. Falagas ME, Tansarli GS, Ikawa, Vardakas KZ: Clinical outcomes with extended or continuous versus short-term intravenous infusion of carbapenems and piperacillin/tazobactam: a systematic review and meta-analysis. Clin Infect Dis 2013, 56:272-282.

8. DerSimonian R, Laird N: Meta-analysis in clinical trials. Control Clin Trials 1986, 7:177-188.

9. Higgins JP, Thompson SG, Deeks JJ, Altman DG: Measuring inconsistency in meta-analysis. BMJ 2003, 327:557-560.

10. Hozo SP, Djulbegovic B, Hozo I: Estimating the mean and variance from the median, range, and the size of a sample. BMC Med Res Methodol 2005, 5:13.

11. The Cochrane Handbook. Available at http://handbook.cochrane.org/ Home > Part 2: General methods for Cochrane reviews $>7$ Selecting studies and collecting data $>7.7$ Extracting study results and converting to the desired format > 7.7.3 Data extraction for continuous outcomes > 7.7.3.5 Medians and interquartile ranges.

12. Georges B, Archambaud M, Saivin S, Decun JF, Cougot P, Mazerolles M, Andrieu P, Suc CH, Houin G, Chabanon G, Verenque $\mathrm{CH}$ : Continuous versus intermittent cefepime infusion in critical care patients: preliminary findings. Pathol Biol 1999, 47:483-485.

13. Hanes SD, Wood GC, Herring V, Croce MA, Fabian TC, Pritchard E, Boucher BA: Intermittent and continuous ceftazidime infusion for critically ill trauma patients. Am J Surg 2000, 179:436-440.

14. Nicolau DP, McNabb J, Lacy MK, Quintiliani R, Nightingale CH: Continuous versus intermittent administration of ceftazidime in intensive care unit patients with nosocomial pneumonia. Int J Antimicrob Agents 2001, 17:497-504.

15. Wysocki M, Delatour F, Faurisson F, Rauss A, Pean Y, Misset B, Thomas F, Timsit J-F, Similowski T, Mentec H, Mier L, Dreyfuss D: Continuous versus intermittent infusion of vancomycin in severe staphylococcal infections: prospective multicenter randomized study. Antimicrob Agents Chemother 2001, 45:2460-2467.

16. Buijk SLCE, Gyssens IC, Mouton, Mouton JW, Van Vliet A, Verbrugh HA, Bruining HA: Pharmacokinetics of ceftazidime in serum and peritoneal exudates during continuous versus intermittent administration to patients with severe intra-abdominal infections. J Antimicrob Chemother 2002, 49:121-128.

17. Georges B, Conil JM, Cougot P, Decun JF, Archambaud M, Seguin T, Chabanon G, Virenque C, Houin G, Saivin S: Cefepime in critically ill patients: continuous infusion vs. an intermittent dosing regimen. Int $J$ Clin Pharmacol Ther 2005, 43:360-369.

18. Rafati MR, Rouini MR, Mojtahedzadeh M, Najafi A, Tavakoli H, Gholami K, Fazeli MR: Clinical efficacy of continuous infusion of piperacillin compared with intermittent dosing in septic critically ill patients. Int J Antimicrob Agents 2006, 28:122-127.

19. Roberts JA, Boots R, Rickard CM, Thomas P, Quinn J, Roberts DM, Richards B, Lipman J: Is continuous infusion ceftriaxone better than once-a-day dosing in intensive care? A randomized controlled pilot study. $J$ Antimicrob Chemother 2007, 59:285-291.

20. Sakka SG, Glauner AK, Bulitta JB, Kinzig-Schippers M, Pfister W, Drusano GL, Sorgel F: Population pharmacokinetics and pharmacodynamics of continuous versus short-term infusion of imipenem-cilastatin in critically ill patients in a randomized, controlled trial. Antimicrob Agents Chemother 2007, 51:3304-3310.

21. Adembri C, Fallani S, Cassetta Ml, Arrigucci S, Ottaviano A, Pecile P, Mazzei T, De Gaudio R, Novelli A: Linezolid pharmacokinetic/pharmacodynamic profile in critically ill septic patients: intermittent versus continuous infusion. Int J Antimicrob Agents 2008, 31:122-129.

22. Chytra I, Stepan M, Benes J, Pelnar P, Zidkova A, Bergerova T, Pradl R, Kasal E: Clinical and microbiological efficacy of continuous versus intermittent application of meropenem in critically ill patients: a randomized open-label controlled trial. Crit Care 2012, 16:R113.

23. Schentag JJ, Smith IL, Swanson DJ: Role for dual individualization with cefmenoxime. Am J Med 1984, 77:43-50.

24. Lorente L, Lorenzo L, Martin MM, Jimenez A, Mora ML: Meropenem by continuous versus intermittent infusion in ventilator-associated pneumonia due to gram-negative bacilli. Ann Pharmacother 2006, 40:219-223.

25. Lodise TP Jr, Lomaestro B, Drusano GL: Piperacillin-tazobactam for Pseudomonas aeruginosa infection: clinical implications of an extended-infusion dosing strategy. Clin Infect Dis 2007, 44:357-363.

26. Lorente L, Jimenez A, Palemero S, Jimenez JJ, Iribarren JL, Santana M, Martin MM, Mora ML: Comparison of clinical cure rates in adults with ventilator-associated pneumonia treated with intravenous ceftazidime administered by continuous or intermittent infusion: a retrospective, nonrandomized, open-label, historical chart review. Clin Ther 2007, 29:2433-2439. 
27. Nicasio AM, Eagye K, Nicolau DP, Shore E, Palter M, Pepe J, Kuti JL: Pharmacodynamic-based clinical pathway for empiric antibiotic choice in patients with ventilator-associated pneumonia. J Crit Care 2010, 25:69-77.

28. Yost RJ, Cappelletty DM, RECEIPT Study group: RECEIPT Study group: The Retrospective Cohort of Extended-Infusion Piperacillin-Tazobactam (RECEIPT) study: a multicenter study. Pharmacotherapy 2011, 31:767-775.

29. Dulhunty JM, Roberts JA, Davis JS, Webb SA, Bellomo R, Gomersall C, Shirwadkar C, Eastwood GM, Myburgh J, Paterson DL, Lipman J: Continuous infusion of beta-lactam antibiotics in severe sepsis: a multicenter double-blind, randomized controlled trial. Clin Infect Dis 2013, 56:236-244.

30. Dow RJ, Rose WE, Fox BC, Thorpe JM, Fish JT: Retrospective study of prolonged versus intermittent infusion piperacilin-tazobactam and meropenem in intensive care unit patients at an academic medical center. Infect Dis Clin Pract 2011, 19:413-417

31. Lorente $L$, Jimenez A, Martin MM, Iribarren $J L$, Jimenez JJ, Mora ML: Clinical cure of ventilator-associated pneumonia treated with piperacillin/tazobactam administered by continuous or intermittent infusion. Int J Antimicrob Agents 2009, 33:464-468

32. Wang D: Experience with extended-infusion meropenem in the management of ventilator-associated pneumonia due to multidrug-resistant Acinetobacter baumannii. Int J Antimicrob Agents 2009, 33:287-294.

33. Itabashi S: Clinical efficacy of prolonged (4 hour) drip infusion of meropeneme against severe pneumonia. Japan J Antibiotics 2007, 170:60-63.

34. Akers KS, Cota JM, Chung KK, Renz EM, Mende K, Murray CK: Serum vancomycin levels resulting from continuous or intermittent infusion in critically ill burn patients with or without continuous renal impairment therapy. J Burn Care Res 2012, 33:e254-e262.

35. Lee GC, Liou H, Yee R, Quan CF, Neldner K: Outcomes of extended-infusion piperacillin-tazobactam: a retrospective analysis of critically ill patients. Clin Ther 2012, 24:2297-2300.

36. Arnold HM, Hollands JM, Skrupky LP, Smith JR, Juang PH, Hampton NB, McCormick S, Reichley RM, Hoban A, Hoffman J, Micek ST, Kollef MH: Prolonged infusion antibiotics for suspected gram-negative infections in the ICU: a before-after study. Ann Pharmacother 2013, 47:170-180.

37. Hsaiky L, Murray KP, Kokoska L, Desai N, Cha R: Standard versus prolonged doripenem infusion for treatment of gram-negative infections. Ann Pharmacother 2013, 47:999-1006.

38. Chapuis TM, Giannoni E, Majcherczyk PA, Chiolero R, Schaller MD, Berger MM, Bolay S, Decosterd LA, Burnon D, Moreillon P: Prospective monitoring of cefepime in intensive care unit adult patients. Crit Care 2010, 14:R51.

39. Roberts JA, Ulldemolins M, Roberts MS, McWhinney B, Ungerer J, Paterson DL, Lipman J: Therapeutic drug monitoring of beta-lactams in critically ill patients: proof of concept. Int J Antimicrob Agents 2010, 36:332-339.

40. Roberts JA, Roberts MS, Robertson TA, Dalley AJ, Lipman J: Piperacillin penetration into tissue of critically ill patients with sepsis: bolus versus continuous administration? Crit Care Med 2009, 37:926-933.

41. Rea RS, Capitano B, Bies R, Bigos KL, Smith R, Lee H: Suboptimal aminoglycoside dosing in critically ill patients. Ther Drug Monit 2008, 30:674-681.

42. Del Mar Fernandez De Gatta Garcia M, Revilla N, Calvo MV, Dominguez-Gi A, Sanchez Navarro A: Pharmacokinetic/pharmacodynamic analysis of vancomycin in ICU patients. Intensive Care Med 2007, 33:279-285.

43. Fish DN: Evaluation of gatifloxacin pharmacokinetics and pharmacodynamics in severely ill adults in medical Intensive Care Unit. Int J Antimicrob Agents 2007, 29:715-723.

44. Roos JF, Lipman J, Kirkpatrick CM: Population pharmacokinetics and pharmacodynamics of cefpirome in critically ill patients against Gram-negative bacteria. Intensive Care Med 2007, 33:781-788.

45. Roos JF, Bulitta J, Lipman J, Kirkpatrick CM: Pharmacokineticpharmacodynamic rationale for cefepime dosing regimens in intensive care units. J Antimicrob Chemother 2006, 58:987-993.

46. Boselli E, Breilh D, Rimmele T, Djabarouti S, Saux M-C, Chassard D, Allaouchiche B: Pharmacokinetics and intrapulmonary diffusion of levofloxacin in critically ill patients with severe community-acquired pneumonia. Crit Care Med 2005, 33:104-109.

47. Navarro AS, Gandarillas C-IC, Lerma FA, Menacho YA, Dominguez-Gil A: Pharmacokinetics and pharmacodynamics of levofloxacin in intensive care patients. Clin Pharmacokinet 2005, 44:627-635.

48. Barbot A, Venisse N, Rayeh F, Bouquet S, Debaene B, Mimoz O: Pharmacokinetics and pharmacodynamics of sequential intravenous and subcutaneous teicoplanin in critically ill patients without vasopressors. Intensive Care Med 2003, 29:1528-1534.
49. Pea F, Di QE, Cusenza A, Brollo L, Baldassarre M, Furlanut M: Pharmacokinetics and pharmacodynamics of intravenous levofloxacin in patients with early-onset ventilator-associated pneumonia. Clin Pharmacokinet 2003, 42:589-598.

50. Benko R, Matuz M, Doro P, Peto Z, Molnar A, Hajdu E, Nagy E, Gardi J, Soos G: Pharmacokinetics and pharmacodynamics of levofloxacin in critically ill patients with ventilator-associated pneumonia. Int J Antimicrob Agents 2007, 30:162-168.

51. Pea F, Poz D, Viale P, Pavan F, Furlanut M: Which reliable pharmacodynamic breakpoint should be advised for ciprofloxacin monotherapy in the hospital setting? A TDM-based retrospective perspective. J Antimicrob Chemother 2006, 58:380-386.

52. Jaruratanasirikul S, Sriwiriyajan S, Punyo J: Comparison of the pharmacodynamics of meropenem in patients with ventilator-associated pneumonia following administration by 3-hour infusion or bolus injection. Antimicrob Agents Chemother 2005, 49:1337-1339.

53. Kitzes-Cohen R, Farin D, Piva G, De Myttenaere-Bursztein SA: Pharmacokinetics and pharmacodynamics of meropenem in critically ill patients. Int J Antimicrob Agents 2002, 19:105-110.

54. Lipman J, Gomersall CD, Gin T, Joynt GM, Young RJ: Continuous infusion ceftazidime in intensive care: a randomized controlled trial. J Antimicrob Chemother 1999, 43:309-311.

55. Thalhammer F, Traunmüller F, El Menyawi I, Frass M, Hollenstein UM, Locker GJ, Stoiser B, Staudinger T, Thalhammer-Scherrer R, Burgmann H: Continuous infusion versus intermittent administration of meropenem in critically ill patients. J Antimicrob Chemother 1999, 43:523-527.

56. Benko AS, Cappelletty DM, Kruse JA, Rybak MJ: Continuous infusion versus intermittent administration of ceftazidime in critically ill patients with suspected gram-negative infections. Antimicrob Agents Chemother 1996, 40:691-695.

57. Nicolau DP, McNabb J, Lacy MK, Li J, Quintiliani R, Nightingale CH: Pharmacokinetics and pharmacodynamics of continuous and intermittent ceftazidime during the treatment of nosocomial pneumonia. Clin Drug Invest 1999, 18:133-139.

58. Nicolau DP, Lacy MK, McNabb J, Quintiliani $\mathrm{R}$, Nightingale $\mathrm{CH}$ : Pharmacokinetics of continuous and intermittent ceftazidime in intensive care unit patients with nosocomial pneumonia. Infect Dis Clin Pract 1999, 8:45-49.

59. Duszynska W, Taccone FS, Switala M, Hurkacz M, Kowalska-Krochmal B, Kubler A: Continuous infusion of piperacillin/tazobactam in ventilator-associated pneumonia: a pilot study on efficacy and costs. Int J Antimicrob Agents 2012, 39:153-158.

60. Fish DN, Teitelbaum I, Abraham E: Pharmacokinetics and pharmacodynamics of imipenem during continuous renal replacement therapy in critically ill patients. Antimicrob Agents Chemother 2005, 49:2421-2428

61. Suyama H, Ikawa K, Morikawa N, Ikeda K, Fujiue Y, Morikawa S, Kaneko K, Kuwabara M, Yamanoue T: Pharmacokinetics and pharmacodynamics of biapenem in critically ill patients under continuous venovenous hemodiafiltration. Japan J Antibiotics 2008, 61:303-313.

62. Roberts JA, Kirkpatrick CM, Roberts MS, Dalley AJ, Lipman J: First-dose and steady-state population pharmacokinetics and pharmacodynamics of piperacillin by continuous or intermittent dosing in critically ill patients with sepsis. Int J Antimicrob Agents 2010, 35:156-163.

63. Vilay AM, Grio M, Depestel DD, Sowinski KM, Gao L, Heung M, Salama NN, Mueller BA: Daptomycin pharmacokinetics in critically ill patients receiving continuous venovenous hemodialysis. Crit Care Med 2011, 39:19-25.

64. Cousson J, Floch T, Vernet-Garnier V, Appriou M, Petit JS, Jovenin N, Lamiable D, Hoizey G: Pharmacodynamic interest of ceftazidime continuous infusion vs intermittent bolus administration in patients with severe nosocomial pneumonia [French]. Pathol Biol 2005, 53:546-550.

65. Haque NZ, Zuniga LC, Peyrani P, Reyes K, Lamerato L, Moore CL, Patel S, Allen M, Peterson E, Wiemken T, Cano E, Mangino JE, Kett DH, Ramirez JA, Zervos MJ: Relationship of vancomycin minimum inhibitory concentration to mortality in patients with methicillin-resistant Staphylococcus aureus hospital-acquired, ventilator-associated, or healthcare-associated pneumonia. Chest 2010, 138:1356-1362.

66. Lorenzen JM, Broll M, Kaever V, Burhenne H, Hafer C, Clajus C, Knitsch W, Burkhardt O, Kielstein JT: Pharmacokinetics of ampicillin/sulbactam in critically ill patients with acute kidney injury undergoing extended dialysis. Clin J Am Soc Nephrol 2012, 7:385-390. 
67. Ocampos-Martinez E, Penaccini L, Scolletta S, Abdelhadii A, Devigili A, Cianferoni S, de Backer D, Jacobs F, Cotton F, Vincent JL, Taccone FS: Determinant of early inadequate vancomycin concentrations during continuous infusion in septic patients. Int J Antimicrob Agents 2012, 39:332-337.

68. Baptista JP, Sousa E, Martins PJ, Pimentel JM: Augmented renal clearance in septic patients and implications for vancomycin optimization. Int J Antimicrob Agents 2012, 39:420-423.

69. Boselli E, Breilh D, Caillault-Sergent A, Djabarouti S, Guillaume C, Xuereb F, Bouvet L, Rimmelé T, Saux MC, Allaouchiche B: Alveolar diffusion and pharmacokinetics of linezolid administered in continuous infusion to critically ill patients with ventilator-associated pneumonia. J Antimicrob Chemother 2012, 67:1207-1210.

70. Cade JF, Presneill J, Sinickas V, Hellyar A: The optimal dosage of ceftazidime for severe lower respiratory tract infections. J Antimicrob Chemother 1993, 32:611-622.

71. Cade JF, Presneill J, Keighley C, Sinickas V: Efficacy of a low dose of cefotaxime in serious chest infections. Chest 1992, 101:1393-1398.

72. Schwigon CD, Hulla FW, Schulze B, Maslak A: Timentin in the treatment of nosocomial bronchopulmonary infections in intensive care units. J Antimicrob Chemother 1986, 17:115-122.

73. van Zanten AR, Polderman KH, van Geijlswijk IM, van der Meer GY, Schouten MA, Girbes AR: Ciprofloxacin pharmacokinetics in critically ill patients: a prospective cohort study. J Crit Care 2008, 23:422-430.

74. Arzuaga A, Maynar J, Gascón AR, Isla A, Corral E, Fonseca F, Sánchez-Izquierdo JA, Rello J, Canut A, Pedraz JL: Influence of renal function on the pharmacokinetics of piperacillin/tazobactam in intensive care unit patients during continuous venovenous hemofiltration. J Clin Pharmacol 2005, 45:168-176.

75. Eagye KJ, Kuti JL, Sutherland CA, Eagye KJ, Kuti JL, Sutherland CA, Christensen $\mathrm{H}$, Nicolau DP: In vitro activity and pharmacodynamics of commonly used antibiotics against adult systemic isolates of Escherichia coli and Pseudomonas aeruginosa at forty US Hospitals. Clin Ther 2009, 31:2678-2688.

76. Mouton JW, Punt N, Vinks AA: A retrospective analysis using Monte Carlo simulation to evaluate recommended ceftazidime dosing regimens in healthy volunteers, patients with cystic fibrosis, and patients in the intensive care unit. Clin Ther 2005, 27:762-772.

77. Tam VH, Louie A, Lomaestro BM, Drusano GL: Integration of population pharmacokinetics, a pharmacodynamic target, and microbiologic surveillance data to generate a rational empiric dosing strategy for cefepime against Pseudomonas aeruginosa. Pharmacotherapeutics 2003, 23:291-295.

78. Goss TF, Forrest A, Nix DE, Ballow CH, Birmingham MC, Cumbo TJ, Schentag JJ: Mathematical examination of dual individualization principles (II): the rate of bacterial eradication at the same area under the inhibitory curve is more rapid for ciprofloxacin than for cefmenoxime. Ann Pharmacother 1994, 28:863-868.

79. Zelenitsky SA, Ariano RE, Zhanel GG: Pharmacodynamics of empirical antibiotic monotherapies for an intensive care unit (ICU) population based on Canadian surveillance data. J Antimicrob Chemother 2011, 66:343-349.

80. Roberts JA, Kirkpatrick CM, Roberts MS, Robertson TA, Dalley AJ, Lipman J: Meropenem dosing in critically ill patients with sepsis and without renal dysfunction: intermittent bolus versus continuous administration? Monte Carlo dosing simulations and subcutaneous tissue distribution.

J Antimicrob Chemother 2009, 64:142-150.

81. Revilla N, Martin-Suarez A, Perez MP, Gonzalez FM, Fernandez de Gatta Mdel M: Vancomycin dosing assessment in intensive care unit patients based on a population pharmacokinetic/pharmacodynamic simulation. Br J Clin Pharmacol 2010, 70:201-212.

82. Nicasio AM, Eagye K, Kuti EL, Nicolau DP, Kuti JL: Length of stay and hospital costs associated with a pharmacodynamic-based clinical pathway for empiric antibiotic choice for ventilator-associated pneumonia. Pharmacotherapeutics 2010, 30:453-462.

83. McNabb JJ, Nightingale CH, Quintiliani R, Nicolau DP: Cost-effectiveness of ceftazidime by continuous infusion versus intermittent infusion for nosocomial pneumonia. Pharmacotherapeutics 2001, 21:549-555.

84. Moriyama B, Henning SA, Neuhauser MM, Danner RL, Walsh TJ: Continuous-infusion beta-lactam antibiotics during continuous venovenous hemofiltration for the treatment of resistant gram-negative bacteria. Ann Pharmacother 2009, 43:1324-1337.
85. Mah GT, Mabasa VH, Chow I, Ensom MHH: Evaluation outcomes associated with alternative dosing strategies for piperacillin/tazobactam: a qualitative systematic review. Ann Pharmacother 2012, 46:265-275.

86. Le Gall JR, Loirat P, Alperovitch A, Glaser P, Granthil C, Mathieu D, Mercier P, Thomas R, Villers D: A simplified acute physiology score for ICU patients. Crit Care Med 1984, 12:975-977.

87. Ferreira FL, Bota DP, Bross A, Melot C, Vincent JL: Serial evaluation of the SOFA score to predict outcome in critically ill patients. JAMA 2001, 286:1754-1758.

88. Knaus WA, Draper EA, Wagner DP, Zimmermann JE: APACHE II: a severity of disease classification system. Crit Care Med 1985, 13:818-829.

89. Le Gall JR, Lemeshow S, Saulnier F: A new Simplified Acute Physiology Score (SAPS II) based on a European/North American multicenter study. JAMA 1993, 270:2957-2963. Erratum, JAMA 1994, 271:1321.

90. Mackinnon PS, Paladino JA, Schentag JJ: Evaluation of area under the inhibitory curve (AUIC) and time above the minimum inhibitory concentration ( $\mathrm{T}>\mathrm{MIC}$ ) as predictors of outcome for cefipime and ceftazidime in serious bacterial infections. Int J Antimicrob Agents 2008, 31:345-351.

91. Roberts DM, Roberts JA, Roberts MS, Liu Z, Nair P, Cole L, Lipman J, Bellomo R, RENAL Replacement Therapy Study Investigators: Variability of antibiotic concentrations in critically ill patients receiving continuous renal replacement therapy: a multicentre pharmacokinetic study. Crit Care Med 2012, 40:1523-1528.

92. Udy AA, Varghese JM, Altukroni M, Briscoe S, McWhinney BC, Ungerer JP, Lipman J, Roberts JA: Subtherapeutc initial $\beta$-lactam concentrations in select critically ill patients: association between augmented renal clearance and low trough drug concentrations. Chest 2012, 142:30-39.

93. Moher D, Liberati A, Tetzlaff J, Altman DG, PRISMA Group: Preferred reporting items for systematic reviews and meta-analyses: the PRISMA Statement. Ann Intern Med 2009, 151:264-269.

94. Hróbjartsson A, Thomsen AS, Emanuelson F, Tendal B, Hilden J, Boutron I, Ravaud $\mathrm{P}$, Brorson S: Observer bias in randomized clinical trials with measurement scale outcomes: a systematic review of trials with both blinded and non-blinded assessors. CMAJ 2012, 185:E201-E211.

95. Kollef M, Chastre J, Clavel M, Restrepo MI, Michiels B, Kaniga K, Cirillo I, Kimko H, Redman R: A randomized trial of 7-day doripenem versus 10 day imipenem-cilastatin for ventilator-associated pneumonia. Crit Care 2012, 16:R218

doi:10.1186/cc13134

Cite this article as: Chant et al:: Optimal dosing of antibiotics in critically ill patients by using continuous/extended infusions: a systematic review and meta-analysis. Critical Care 2013 17:R279.

\section{Submit your next manuscript to BioMed Central and take full advantage of:}

- Convenient online submission

- Thorough peer review

- No space constraints or color figure charges

- Immediate publication on acceptance

- Inclusion in PubMed, CAS, Scopus and Google Scholar

- Research which is freely available for redistribution 